Instructions for authors, subscriptions and further details:

http://brac.hipatiapress.com

\title{
El holograma como Experiencia Artística
}

Angel Alonso ${ }^{1}$

1) Crítico de arte y artista plástico, La Habana (Cuba)

Date of publication: June $3^{\text {rd }}, 2016$

Edition period: June 2016 - October 2016

To cite this article: Alonso, A. (2016). El holograma como experiencia artística. Barcelona, Research, Art, Creation, 4(2), 168-186. doi: 10.17583/ brac. 2016.1700

To link this article: http://dx.doi.org/10.17583/brac.2016.1700

\section{PLEASE SCROLL DOWN FOR ARTICLE}

The terms and conditions of use, except where otherwise noted, are related to the Open Journal System and to Creative Commons Attribution License (CCBY). The indication must be expressly stated when necessary. 
BRAC - Barcelona Research Art Creation. Vol. 4 No. 2, June 2016, pp. 168-186

\title{
The Hologram as an Artistic Experience
}

\author{
Angel Alonso \\ Art critic and artist, La Habana (Cuba)
}

(Received: 27 August 2015; Accepted: 4 May 2016; Published: 3 June 2016)

\begin{abstract}
Holography has been used as a way of artistic expression, but it has little presence in art events, neither in articles about holographic woks in specialized magazines are very common, although valuable creators have experienced it, since the catalán Salvador Dalí to the american Bruce Nauman.

This text explorer the cause of this poor presence. It's strange that something so attractive and visually rich (also simbolically) is not visible in our historical moment, characterized by the voracity of convert in artistic resource any possible element.

After research about the development of holographyc on the field of art, I formed a hypothesis about the reasons of their limited presence: The lack of synergy between scientific institutions and those dedicated to art, the disinterest of the commissioners and the lack of information. It is not enough whit the objects that are produced by isolated artists in their studios, art is a system of relationships where the work is involved as an other element of a structure.
\end{abstract}

Keywords: Art, hologram, science, visual, virtual reality 
BRAC - Barcelona Research Art Creation. Vol. 4 No. 2, June 2016, pp. 168-186

\title{
El holograma como Experiencia Artística
}

\author{
Angel Alonso \\ Crítico de arte y artista plástico, La Habana (Cuba)
}

(Recibido: 27 Agosto 2015; Aceptado: 4 Mayo 2016; Publicado: 3 Junio 2016)

\section{Resumen}

La holografía se ha utilizado como medio de expresión artística, pero su presencia es escasa en los eventos de arte, tampoco abundan artículos sobre obras holográficas en las revistas especializadas, a pesar de que valiosos creadores la han experimentado, desde el catalán Salvador Dalí hasta el norteamericano Bruce Nauman.

El presente texto indaga en las causas de esta tímida presencia. Resulta extraño que algo tan atractivo y de tanta riqueza visual (también simbólica) no se haga visible en nuestro momento histórico, caracterizado por la voracidad de convertir en recurso artístico cualquier elemento posible.

Después de una investigación sobre el desarrollo de la holografía en el campo del arte, concluyo con una hipótesis sobre los motivos de su escasa presencia: La ausencia de sinergia entre las instituciones científicas y las dedicadas al arte, el desinterés de los comisarios y la falta de información. No basta con los objetos que produzcan los artistas aislados en sus estudios, el arte es un sistema de relaciones donde participa la obra como un elemento más de una estructura

Palabras clave: Arte,holograma,ciencia,visuales,realidad virtual 


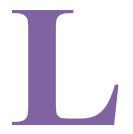

a holografía es una especial técnica fotográfica capaz de representar un objeto en tres dimensiones. Su inventor, Dennis Gabor, estaba interesado en mejorar la resolución del microscopio electrónico y con este objetivo como premisa descubrió, casualmente, un nuevo modo de producir imágenes. El descubrimiento, que tuvo lugar en 1947 y fue registrado un año más tarde en su artículo A new microscopic principle (Gabor, 1948), le proporcionó al científico húngaro el premio Nobel de Física veinticinco años más tarde.

Es con las investigaciones posteriores de Yuri Denisyuk y Emmett N. Leith que puede hablarse de una verdadera representación tridimensional, pues los hologramas de Gabor no contaban con fuentes de luz adecuadas como para que se produjeran los resultados ocasionados por la aparición y el desarrollo del láser (Caufield, 2016). Lo maravilloso de este invento es que superó los límites de la fotografía (su condición bidimensional) para entregarnos una imagen de tres dimensiones que causa la impresión de que el objeto está físicamente allí.

El hecho de que la imagen reconstruida con un holograma sea tridimencional, muestra que este contiene más información sobre la forma de un objeto que una fotografía vulgar. ¿Por qué? Una fotografía común registra solo las variaciones de intensidad de la luz reflejadas por un objeto. Las zonas claras del objeto reflejan más luz y producen regiones oscuras en el negativo. Las partes oscuras del objeto producen el efecto contrario. Un holograma registra no solo variaciones de intensidad sino también de fase en función a la profundidad del objeto (Viera \& Ferreira, 2006)

La tridimensionalidad del holograma prevalece también por encima del efecto óptico de la estereoscopía, cuyos principios se aplican aún en el cine $3 \mathrm{D}$ y que consiste, en esencia, en crear una ilusión de profundidad mediante la visión de dos imágenes planas (una para el ojo izquierdo y la otra para el derecho), casi exactas, solo diferenciadas por la pequeña variación de ángulo visual que condiciona la distancia entre ambos ojos (Fernández, 2004. pp. 120-121). Es probable que muchos confundan lo que ocurre en la holografía 
con lo que ocurre en el cine de tres dimensiones pero en verdad se trata de dos cosas bien diferentes. Cuando vemos una película en 3D distinguimos una sensación de tridimensionalidad a partir de dos imágenes planas, proyectadas por separado pero superpuestas en nuestra percepción. Un holograma es algo conceptualmente mucho más "real", es la traducción de un código encriptado; al iluminarse la placa se proyecta la imagen en el espacio. Esa imagen realmente está allí aunque no pueda tocarse.

El cine 3D crea una ilusión de profundidad, pero al aguzar los sentidos notamos que bajo el hechizo de dicho artilugio no podemos cambiar nuestra posición con respecto al objeto representado. Si desde la pantalla el personaje nos apunta con un revolver el efecto será el mismo para el espectador sentado a la izquierda de la sala que para el que ocupe una silla a la derecha. Si fuese un holograma ambos espectadores tendrían una visión diferente y solo quien se sentase en el centro quedaría apuntado por el arma en cuestión.

Por supuesto, en ambos casos se trata de una sensación de tridimensionalidad en el que mira, pero esa misma alucinación ya germinaba en el uso de la perspectiva como método ilusorio de la Pintura. Estas diferenciaciones ya no las hacemos a causa de nuestra atrofiada capacidad de asombro, esa que desafiaron los hermanos Lumière cuando los asistentes a las proyecciones salían espantados del cine pensando que la locomotora de la pantalla los atropellaría, o cuando los curiosos miraban al dorso de la inmensa tela para ver cual era el truco.

En la holografía, al igual que en la fotografía, se genera una imagen en una película. Solo que la fotografía corresponde a un solo punto de vista y lo que vemos en ella tiene dos dimensiones, mientras que el holograma es un sistema de códigos grabados en una placa que traduce el modelo a su imagen tridimensional, reconoce y abarca toda la información visual que procede del objeto y su contexto, fructifica por el carácter ondulatorio de la luz, por la intersección de sus ondas, se trata de una imagen multidimensional. Es la utopía cubista realizada, al menos en lo que atañe al intento de ese movimiento -verdadera revolución en la historia de la pintura- de representar todas las partes de un objeto.

La utopía se cumple pero mediante un mecanismo opuesto: Los cubistas, en su rompimiento con la pintura tradicional, arrasan con la visión naturalista y establecen la "perspectiva múltiple" (Cottington, 2002, pp.52-60); el pintor no podía desplazarse y unía en un mismo plano varias visiones de un objeto. El holograma nos da la oportunidad de deslizarnos y observar el objeto desde 
varios puntos de vista como si éste estuviese allí en el espacio. El carácter detenido e invariable de una imagen pictórica o fotográfica es desafiado por el holograma, que involucra el movimiento del público, este se mueve y ve otro ángulo de la intangible escultura de luz; a veces está junto a él en su propio espacio, a veces la placa se ilumina y parece un profundo nicho donde está encajada, en ocasiones parece un bajo relieve...

\section{El Holograma en el Panorama de las Artes Visuales; una Presencia Intermitente}

El holograma, con el tiempo, pasaría a intervenir como muchos otros inventos en el terreno del arte. Esto era lógico que sucediese, pues se trata, más allá de sus valores como avance científico, de una forma de construir imágenes. Desde este punto de vista, se esperaba que ocurriese lo mismo que a la fotografía o al cine, este último considerado hoy el Séptimo Arte, aunque en sus inicios fuese un entretenimiento de feria. No es un secreto que los artistas visuales han sido sumamente abiertos al asumir como materiales de producción todos los medios imaginables. La Video-creación, el Performance o el Arte Digital, son algunos ejemplos de la trasgresión de los lenguajes tradicionales. Obras elaboradas con luces, sonidos, textos, olores... dan fe de la capacidad del Arte Contemporáneo para concebir como posibilidad expresiva cualquier elemento de la materia y hasta de la no materia -recordemos los espacios vacíos del artista francés Yves Klein intercambiados por oro-. "un intercambio simbólico entre el máximo valor material y el mínimo” (Dueñas, 2001).

Se han liberado las fronteras entre las diversas manifestaciones artísticas y hasta las más rancias academias incluyen en sus programas de estudio disciplinas inherentes al uso de los ordenadores como el llamado Net Art. -aquel que opera en Internet hurtándola como escenario para su disfrute y consumo- o el Arte Interactivo -que rompe con la pereza del espectador por tratarse de obras de participación-. Los cursos de Historia del Arte ya no se detienen en el pasado y relatan experiencias coetáneas que devienen, en la mayoría de las ocasiones, del Arte Conceptual pero que no son fácilmente clasificables. Asistimos a un momento histórico en el que el artista escapa a las ya infuncionales etiquetas de los críticos a causa de sus infinitas posibilidades. El panorama, que pudiéramos calificar de cósmico por su diversidad, es inclusivo, depositario de las más osadas mezclas y ajeno a los radicalismos de las vanguardias del Siglo XX, se trata de un reflejo de la fusión que caracteriza 
nuestros tiempos, un fenómeno que se manifiesta en todos los ámbitos de la creación artística y del pensamiento en general. A pesar de esta actitud tan desprendida de normas y tabúes, no encontramos con frecuencia hologramas en las galerías, como tampoco en los más importantes eventos de las artes plásticas.

Los artistas de principios del Siglo XX estuvieron fascinados con la industrialización e incorporaban a sus obras los progresos de la mecánica -la pintura de Fernand Leger es representativa de esta tendencia- pues cada técnica que nace es absorbida y reelaborada como recurso estético. "A Leger le preocupaba dar cuerpo al concepto de un Nuevo Realismo alternativo. Según él cada época artística tiene su propio realismo" (Fer, Batchelor, \& Wood, 1999, p. 264). Los creadores de hoy están tan hechizados por los avances tecnológicos como aquellos que en el ayer se apasionaron con las máquinas. En el cine Fritz Lang (Metrópolis) o Charles Chaplin (Tiempos Modernos) trataron el tema, mientras que en el ámbito de las artes plásticas Francis Picabia y Marcel Duchamp incorporaban el dibujo técnico a sus obras. Era ésta una manera de eludir el placer de la retina y desarrollar el camino inaugurado con la racionalidad matemática de Seurat (luego el historiador del arte Filiberto Menna, estudioso del arte moderno, lo acuñaría como "opción analítica" (Menna, 1977). Con el mismo ímpetu los artistas contemporáneos utilizan las ventajas del mundo digital e incorporan a sus obras vídeo juegos, sensores que generan sonidos y cada recurso que ofrecen los llamados "nuevos medios".

Sin entregarse totalmente a esta técnica, pero incursionando con seriedad en ella, no son pocos los artistas que han realizado hologramas. El catalán Salvador Dalí pretendía superar el relieve pictórico que creía encontrar en las pinturas de Gerard Dou. Cuando Gabor obtiene el Premio Nobel, el artista se había adentrado en la construcción de imágenes estereoscópicas y también había intentado diferentes procedimientos ilusorios como las imágenes dobles. La obra Rostro paranoico (1935) es un ejemplo de su método al que llamaba paranoico-crítico, en ella representa un rostro construido con figuras humanas en un paisaje. Es a partir de este descubrimiento que Dalí se sumerge en su pasión por trascender las limitaciones que encuentra en las dos dimensiones de la pintura. En 1972 la Galería Knoelder de New York exhibió una muestra de sus primeros hologramas (Dalí, 1972). El propio Gabor asistió a la exposición, en la que se vio representado por el entonces inquieto surrealista. Célebres son los hologramas del norteamericano Bruce Nauman, su serie Making Faces (1970) proyecta al artista constriñendo su 
rostro para evidenciar la condición matérica de su carne. Para Nauman este trabajo es una meditación sobre el cuerpo como material (Sharp,1970, pp. 2227). Resultarían imprescindibles en un recuento histórico las obras del escultor francés Maurice Dyens, sobre todo aquellas en las que mediante un ordenador integra diversos lenguajes incluyendo el de la holografía. También han sido muy importantes sus contribuciones para documentar el trabajo realizado por otros artistas, como destaca José Luís Pérez.

En cuanto a lo que se refiere al arte holográfico, el escultor francés Maurice Dyenses es uno de sus máximos exponentes, siendo el responsable de la elaboración en 2002 de la primera y única Enciclopedia Internacional de arte holográfico que está disponible en CD-ROM e incluye los trabajos holográficos de más de un centenar de artistas. Otros artistas que han destacado en este tipo de arte son Moysés Baumstein y los españoles José María Yturralde y Pepe Buitrago (2015).

Otros creadores se han adentrado más en estos procesos como medio de expresión. Los hay muy reconocidos como es el caso de Dieter Jung, artista alemán que ha sido uno de los pioneros en la aplicación de estos medios (Huo, 2010). Bajo una concepción cinética, casi siempre vinculada a la abstracción y a veces incluyendo la figura humana, Jung nos hace partícipe de sus ingeniosas y cambiantes composiciones. También el finlandés Reima Nurmikko se ha destacado por sus obras llenas de humor y sagacidad (Benton, Greguss, Huhtamo, Kac, \& Koski, 1999). Una de ellas, titulada Up and down (2013), exige del espectador flexionar las piernas para ver la segunda de las dos imágenes contenidas en la placa -esto ocurre sin ninguna exhortación escrita al pie de la obra, el público simplemente lo hace en busca de una mejor visión-. En Australia es pionera de estas técnicas Paula Dawson, quien se destaca por sus hologramas de gran formato (Starick, 1995, p. 8). Margaret Benyon es considerada la madre de la holografía británica, comenzó su trabajo a finales de los $60^{\circ}$; estos trascendían el interés puramente científico y fueron valorados como obras de arte (Johnston, 2006). 

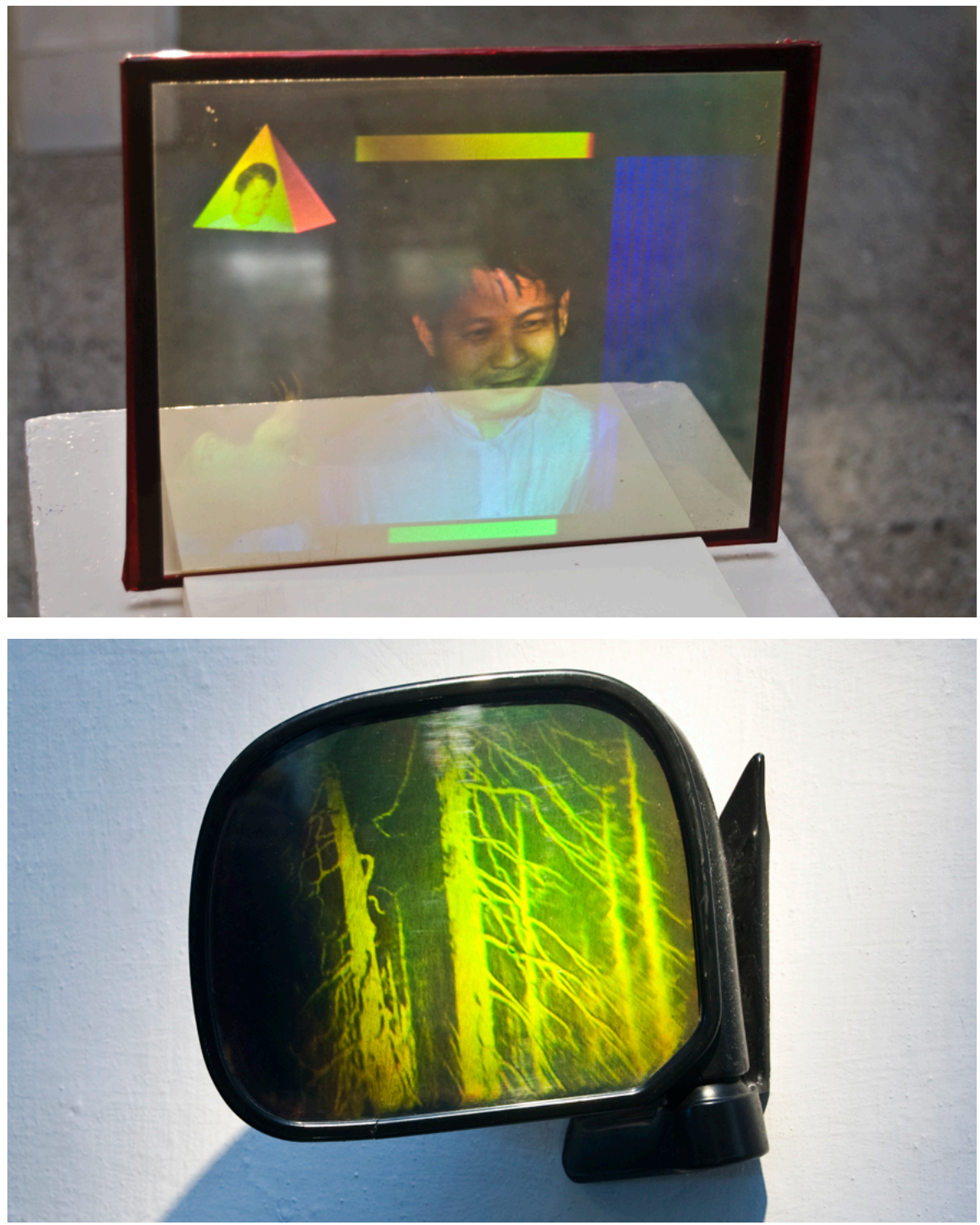

Figura 1. Holograma "The Art Collector" (2013) de Dieter Jung, Fotografía de Alain Cabrera

Figura 2. Holograma "Objects are closer than they appear" (2013) Reima Nurmikko. Fotografía de Alain Cabrera 
Resulta complejo determinar el grado de inmersión con que cada uno de estos artistas ha explorado la holografía para incorporarla a su obra. Desde los que la han utilizado puntualmente (como Nauman) hasta los que han profundizado en ella convirtiéndola en su principal medio de expresión (como Jung), las experiencias han sido disímiles y entremezcladas con el conocimiento adquirido en la práctica de otros lenguajes más tradicionales. Jung no habría sido capaz de hacer sus hologramas abstractos sin un conocimiento previo de la pintura y la escultura, su cinetismo procede de la influencia de artistas cinéticos como Alexander Calder y otros. No contamos con una tradición del arte holográfico al mismo nivel que sí existe una tradición de la pintura o de la escultura, de ahí que no haya un artista del holograma "químicamente puro", todos se expresan o se han expresado en otros lenguajes e incorporan lo aprendido a sus obras holográficas bajo la influencia de la Historia del Arte. Lo que tienen en común muchos de ellos es que son artistas que trabajan a partir de sus ideas y no a partir del medio. No son "máquinas de pintar" ni tampoco "artesanos del holograma", son creadores que buscan el medio más adecuado para expresar sus ideas, y el uso de la holografía ha resultado el más eficaz para algunos de ellos mientras que otros lo han necesitado para obras muy puntuales. No hay entonces una relación directa entre el número de hologramas que realicen y el valor artístico de los mismos, pero llama la atención que son escasos los que convierten esta técnica en su principal recurso expresivo. La producción artística de un período histórico suele encarnar el espíritu de su tiempo asimilando los avances tecnológicos del mismo; en nuestros días nos adentramos, cada vez más, en un mundo de simulaciones que no difiere demasiado del efecto óptico que nos provoca el holograma.

Por asociación a los efectos de la realidad virtual -esa apariencia de veracidad generada a través de los ordenadores- que ha puesto en crisis la barrera entre realidad y ficción, se ha utilizado erróneamente la palabra holograma, pues se ha empleado el término para designar otras proyecciones de apariencia tridimensional. El error se ha extendido al punto de naturalizarse; esto denota una generalizada irresponsabilidad de la prensa (también de la prensa digital) y un vasto desconocimiento de lo que es un holograma en su aspecto tecnológico.

\section{Obstáculos para el Desarrollo de la Holografía en el Arte y sus Posibles Soluciones}

Uno de los factores que atenta contra la popularización de este medio entre 
los creadores es la desinformación. La única referencia a esta técnica con la que cuentan muchas personas es aquella escena de la película La guerra de las Galaxias, cuando la princesa Leia pide ayuda desde una primitiva imagen tridimensional. Esta grabación se repetía como en un disco de vinilo dañado -"Ayúdame Obi Wan Kenobi, tu eres mi única esperanza", (pausa) “Ayúdame Obi Wan Kenobi..." y así sucesivamente-. Lejos estaba George Lucas de imaginar que solo unas décadas después -el filme lo realizaría en 1977-, el adelanto tecnológico superaría con creces, tanto en calidad y definición de imagen como en color, aquella predicción. En Japón, por ejemplo, investigadores de las universidades de Tokio y Osaka, han logrado avances en la producción de hologramas a color que se generan con una común fuente de luz blanca en vez de con láser, una técnica que se diferencia mucho de la holografía tradicional y permite la reducción de costes (Ozaki, Kato \& Kawata, 2013, pp. 6788-6791).

Construir un taller de hologramas puede estimar un gasto de miles de dólares y esta es una causa importante de que estas técnicas no se hayan popularizado, también es cierto que se trata de un procedimiento que requiere un largo aprendizaje. Aún así los costos de fabricación de un holograma están muy por debajo de los invertidos en muchas obras de arte contemporáneo y el artista no tiene que conocer a fondo el proceso técnico del holograma si cuenta con la colaboración del científico para la producción de este tipo de obra.

El trabajo holográfico que hemos citado de Bruce Nauman no hubiera sido posible sin el apoyo de expertos en esta técnica, tampoco Dalí realizó sólo sus hologramas. No es imprescindible, para considerarle autor de una obra holográfica, que el creador haga todo el proceso técnico. Artista es quien crea, quien diseña la imagen, quien emite un discurso artístico a través de un objeto (en este caso) que puede ser elaborado por él mismo pero que también, como el edificio que proyecta un arquitecto, puede ser fabricado por otros. El impresor de un taller de grabado, por ejemplo, garantiza la calidad de la impresión y a menudo posee conocimientos más profundos de los procesos técnicos que el artista que ha dibujado en una piedra litográfica, o que ha grabado la matriz de una xilografía, pero es el artista quien firma la edición. Del mismo modo, la holografía aplicada al arte requiere del intercambio y la colaboración entre disciplinas diferentes, entre el científico y el artista. Este es el aspecto más enriquecedor de esta experiencia porque el artista aprende de física, de óptica...y el físico a su vez se compenetra con la imaginación del creador. 
Por otro lado un holograma convencional como los llamados "de transmisión"-en el que la imagen de luz se encuentra al otro lado del espectadoro "de reflexión"- aquel que toma forma del mismo lado de la placa donde se encuentra el observador- no es más costoso que muchas de las instalaciones expuestas en los eventos artísticos o que muchos murales públicos financiados por ayuntamientos de diversas comunidades. Obras de artistas altamente reconocidos como las de Christo y Jeanne-Claude (Chiappiani, 2006) se llevan a cabo con elevados costos de producción. Solo por poner un ejemplo: para su proyecto "Valley Curtain" (1970-1972), consistente en una tela de 400 $\mathrm{m}$. de largo desplegada sobre un valle, los artistas tuvieron que reunir 230.000 dólares norteamericanos.

Muchos pintores o escultores emergentes sacrifican altas sumas de dinero en contratos anuales con galerías por conceptos de representación, y lo hacen más por ganar un poco de visibilidad que por lo que puedan adquirir con la venta de sus obras. No son pocas las convocatorias de bancos y otras instituciones que disponen de presupuestos suficientes para la ejecución de costosos proyectos. En su Convocatoria del año 2015 Ayudas Fundación BBVA a la Creación en Videoarte, el Banco Bilbao Vizcaya Argentaria estimulaba a los creadores audiovisuales participantes con una dotación de 30.000 euros para la producción de cada una de las 10 obras ganadoras. Algunas de estas ayudas económicas podrían destinarse a financiar la producción de hologramas artísticos, pero ni siquiera se toma en cuenta tal posibilidad, es una zona de la creación extensamente ignorada.

Existen además técnicas muy sencillas de producir un holograma, entre ellas una muy antigua en la que solo se requiere una lámina de acetato o acrílico y una punta de acero (Beaty, 1995). El resto del éxito corresponde a la destreza del artista que manipula estos sencillos instrumentos y a la concepción de la obra. Este método de hacer hologramas a mano es anterior al invento llevado a cabo por Dennis Gabor. En 1934, el artista Hans Weil había patentado un procedimiento para hacer dibujos de luz que parecían flotar en el espacio (Abramson, 2000).

La precaria técnica, que sería luego conocida como Holografía incoherente, es un precedente del holograma tal como lo conocemos hoy. Una fuente de luz puntual procedente de una lámpara produce un destello en una ranura trazada con una punta de acero sobre la superficie empleada (Weil utilizaba láminas de metal). Si el artista ha dividido las líneas de su dibujo en puntos y hace centro en cada uno de ellos por cada arco que traza -en la misma dirección y 
con similar profundidad-, entonces los destellos se unirán organizadamente en su visión y esta línea de puntos brillantes le devolverá el dibujo original en forma de holograma.

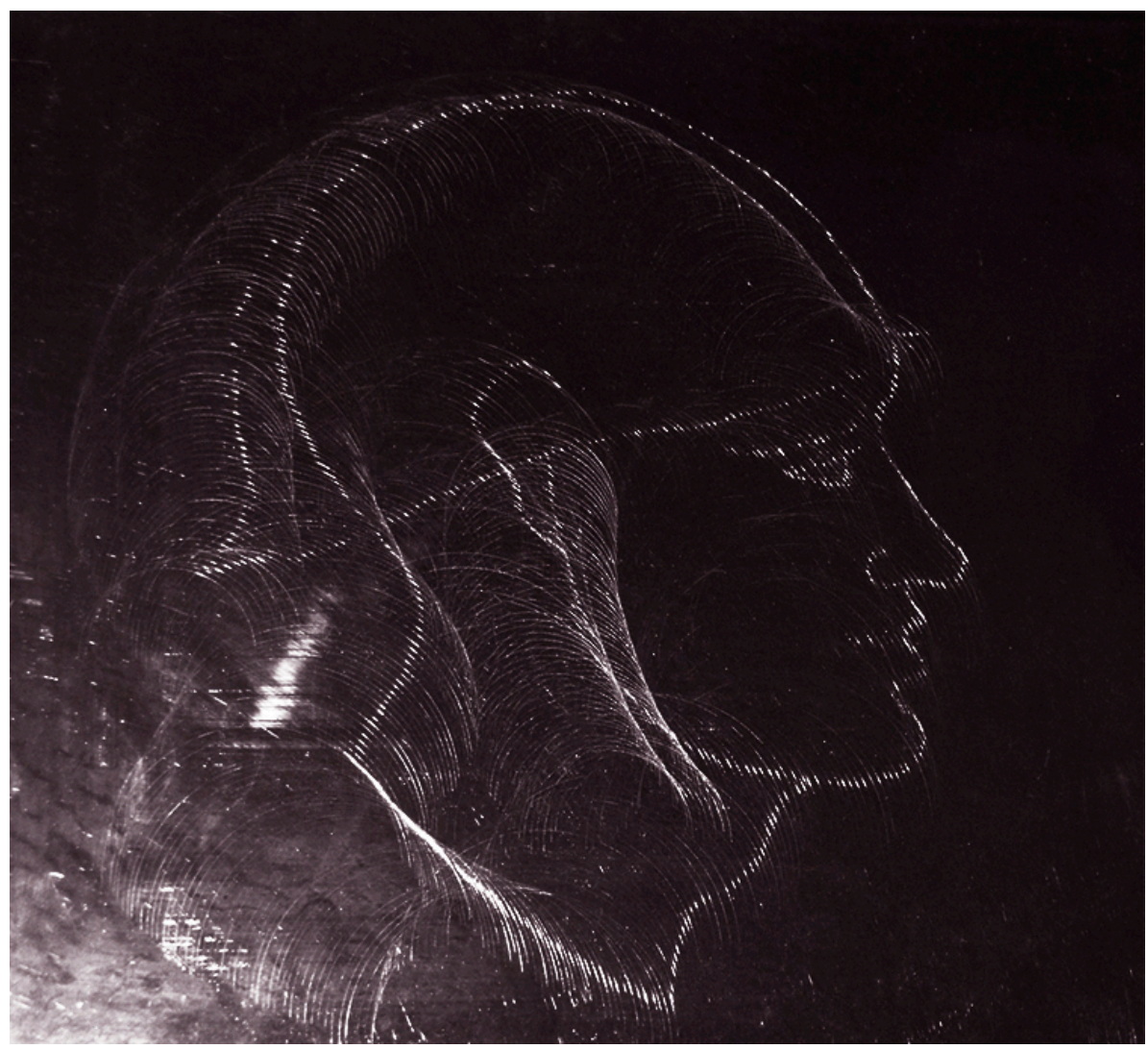

Figura 3. Holograma hecho a mano "Yo no quiero ser un soldado" (2012) de Angel Alonso, fotografía de Alain Cabrera. http://angelalonso-artist.blogspot.com.es/

En 2009 se creó en Cuba una nueva tecnología que constituye la generalización de estos hologramas. En este caso se elabora previamente un diseño en ordenador que es codificado y grabado con láser sobre un material conveniente, lo que permite su aplicación como grabados holográficos, con 
amplias posibilidades como herramienta artística. Sus creadores fueron Ángel G. Augier Calderín y Raúl B. Sánchez. "La creación de esta tecnología e introducción de este tipo de hologramas, generados por ordenador y grabados directamente con láser, ensancha las técnicas holográficas existentes, instaurando nuevas posibilidades de aplicación." (Augier, 2013, p. 14)

Es frecuente encontrar hologramas de alta calidad técnica en los museos históricos, su destino como reproducciones es sustituir valiosas piezas reales en las salas de exhibición y este carácter mimético está lejos de las funciones de la obra de arte. La holografía ha llegado a ser considerada un medio de expresión artística más, aún cuando no se haya popularizado como tal. Arte, ciencia y tecnología se han tomado de la mano a través de los tiempos, no solo a partir del Renacimiento -hemos trascendido la posición de apreciar el fenómeno desde la hegemonía occidental- sino desde mucho antes y en todo tipo de sociedades, antes de que estos términos se acuñasen.

Además de la desinformación y las complejidades de tipo económico hay otro factor que atenta contra el uso del holograma en el terreno del arte, se trata de la abundancia de imágenes a las que nos sometemos continuamente, Con la constante mirada a las pantallas de los celulares, el frecuente uso de los ordenadores y otros dispositivos, asistimos a una visualidad tan cargada de imágenes impactantes que nos saturamos de las mismas y no discernimos entre ellas.

A estos factores se suma otro también importante y es la escasa presencia de críticos, curadores y organizadores de eventos artísticos que trabajen en la promoción y difusión de estas obras. Resulta paradójica la tímida presencia de imágenes holográficas en las exposiciones al mismo tiempo que asistimos a un momento histórico tan desprejuiciado, tan proclive a aprovecharlo todo como el del arte actual. En el caso de las bienales contamos con escasa presencia de Arte Holográfico. Un ejemplo interesante es el del artista Shu-Min Lin, quien expuso en el pabellón dedicado a Taiwán de la $49^{\mathrm{a}}$ Bienal de Venecia que tuvo lugar en el año 2001. Su obra titulada Glass Ceiling (1997) consiste en hologramas de personas de más de 40 países colocados sobre el suelo de modo que el espectador puede pisarlos. Las personas están mirando hacia arriba y el espectador camina sobre ellas. Para el artista se trata de hacernos sentir malvados al caminar sobre otras personas, una metáfora de la competitividad de nuestras sociedades (Haupt \& Binder, 2001).

Hay una generalizada indiferencia al tema que aquí tratamos por parte de las instituciones que provienen del mundo del arte y por parte de los promotores del arte. Podemos encontrar textos que hablan del holograma redactados por 
especialistas en física, en óptica...que se publican en revistas científicas, pero no abundan textos elaborados por críticos de arte o comisarios de exposiciones, que contengan una visión de la holografía desde sus posibilidades como medio de expresión artística o que vean la luz en catálogos y libros de arte. No nos llegan a menudo (tampoco a través de las más circuladas revistas de arte) noticias referentes a artistas plásticos que se expresan por medio de hologramas. La falta de interés tiene que ver con la ausencia de un mercado de arte que promueva este tipo de obras, difíciles de vender, no tanto por sus condiciones físicas o de iluminación como por su falta de legitimación en el campo artístico.

Un poderoso mercado capaz de convertir en fuente de dinero desde a una artista de la performance como Marina Abramovic hasta las ideas heredadas de Joseph Beuys, que se las arregla a través de la documentación para vender obras que ni siquiera existen en el plano físico, no ha sido capaz de atrapar en sus redes -ni de estimular- la producción de un arte holográfico. Salvo contados ejemplos no se han incorporado a las salas de subastas estas obras y permanecen casi ajenas a los mecanismos de comercialización.

La holografía sigue habitando mucho más en el terreno científico que en el artístico, y mientras la misma no se naturalice, el artista que hecha mano a este medio corre el riesgo de quedarse en los pantanos de la gratuita experimentación formal; al menos la recepción del público tiende a ser esa cuando el creador utiliza medios poco conocidos. No toda la responsabilidad de la ausencia de difusión de un arte holográfico recae en las instituciones, los comisarios o el mercado; lo atractivo de las imágenes holográficas puede resultar también un elemento en contra de la efectividad de su uso. En el proceso de incorporación de un mecanismo de representación no convencional a su aplicación como medio de expresión hay una etapa de experimentación que ha de ser trascendida, de otro modo no puede explotarse el mismo en toda su potencialidad.

Así ocurrió con la fotografía, primero utilitaria, luego cada vez más utilizada como medio artístico. En el caso del holograma sería bueno realizar una investigación más amplia, que nos diese las claves de cómo es que un medio tan rico, tan especial y lleno de magia, tan susceptible a la elaboración de propuestas interesantes, se encuentra tan relegado, casi ausente del universo visual del arte contemporáneo. 


\section{La Estructura del Holograma como Metáfora}

También las conjeturas sobre la similitud entre la estructura del universo y la del holograma son aprovechables para el arte desde el punto de vista conceptual. Las hipótesis arriesgadas por escritores, artistas y científicos de nuestros tiempos podrán parecernos tan ridículas como risibles parecieron a sus coetáneos las especulaciones de Julio Verne, Nicolás Coopérnico o Leonardo da Vinci, pero si bien en el campo científico se debe proceder con cautela a la hora de legitimar una teoría, en el terreno del arte, por el contrario, podemos jugar -afortunadamente- a ser más crédulos y hacer un uso libre de ella, sin temor a las inexactitudes científicas en que incurra, empleándola como metáfora del discurso artístico, como pretexto para reflexionar, ya que una obra de arte es, sobre todo, una ficción. Hay teorías que describen el universo como un holograma, recordemos que cada fragmento de una placa holográfica contiene la información de la imagen total, es decir que cada parte abarca el todo. En su libro La totalidad y el orden implicado, David Bohm manifiesta la falsedad de un mundo fragmentado (2008).

Así, en vez de decir: "un observador mira un objeto", podemos decir con más propiedad: "se está produciendo una observación dentro de un movimiento no dividido que incluye esas abstracciones que solemos llamar "el ser humano" y "el objeto que él está observando (p. 56)

Afirmaciones como esta, en las que se manifiesta una visión del universo análoga a la imagen holográfica -en cuanto a su condición indivisible- se emparentan con otras avanzadas investigaciones de la física cuántica y con sus planteamientos sobre la existencia de un mundo conectado cuyos elementos son partes de un todo, en el que la separación individual es una ficción. Algo que no difiere mucho de las enseñanzas del hermetismo contenidas en el Kybalión. Entre las teorías que esgrimen varios especialistas hay algunas que manifiestan que nuestra realidad posee solo dos dimensiones y que lo evidenciado como tercera dimensión es una ilusión que emerge de la interacción de estas dos con el tiempo. Ya sabemos por Einstein que el tiempo es un concepto relativo, algo que solo se cobra sentido en relación al sistema de referencia que tenga un observador. Científicos de la Universidad Tecnológica de Viena aseveran la posibilidad de que estemos viviendo dentro de un holograma. "Todo nuestro universo podría ser mucho más plano de 
lo que parece, por lo menos, matemáticamente hablando" (Forbes, 2015). He aquí una de las investigaciones cuya hipótesis pudiera funcionar como metáfora dentro de una exposición de arte holográfico. Las posibilidades son ilimitadas.

\section{Conclusiones}

Etérea y sublime, la imagen holográfica escapa al mercado, a los curadores, y al interés de un público cuyos ojos permanecen ciegos a la belleza de lo diferente. Ávidos de la confortable repetición de lo que ya conocen, los espectadores pasan por alto estas experiencias y los compradores adquieren aquellos productos que reconocen como obras de arte, hechos en aquellos lenguajes que han sido dignificados por el sistema promocional vigente, que lejos de contribuir a la investigación de los discursos artísticos más arriesgados conservan las garantías inofensivas de lo ya establecido.

La expansión de los conocimientos sobre las técnicas holográficas y sus posibilidades en el arte, la difusión mediante clases y talleres sobre los variados mecanismos que existen para hacer hologramas de mínimo costo -casi domésticos, imperfectos a veces pero igualmente válidos como medios de expresión- y la sinergia entre las instituciones artísticas y científicas, serían muy importantes para el desarrollo de la holografía. Sabemos que hay muchos artistas incorporando a sus creaciones estas técnicas pero -como siempre ocurre en el mundo del arte- la producción de la obra no es suficiente. No basta con los objetos que produzcan los artistas aislados en sus estudios, el arte es un sistema de relaciones donde participa la obra como un elemento más de una estructura compuesta por contextos, instituciones, críticos, comisarios, valores de mercado y público (entre otros componentes).

Sin un interés por priorizar el valor cultural de estas -ya no tan nuevasformas de representación, la holografía corre el riesgo de quedarse en manos de comerciantes que solo explotan su faceta espectacular o que promueven como hologramas proyecciones 3D sobre pantalla líquida, aumentando la desinformación y banalizando los verdaderos valores que este recurso posee. Afortunadamente existen instituciones que trabajan por el desarrollo de esta modalidad artística -ya podemos llamarle así-, como es el caso de Dados Negros, Centro de Holografía y Artes en España, Le musee de l'holographie en Francia o el Holocenter, Center for the Holographic Arts en Estados Unidos. Iniciativas como estas abren una ventana esperanzadora.

Cada vez más precisa y potente, ganando en consistencia y color, la imagen 
holográfica seabre camino en todos los espacios de laviday porsupuesto, también en el arte, aunque con una lentitud sorprendente si consideramos el tiempo transcurridodesdelaprimeramuestradehologramas, comoprecisaDadosNegros:

La primera exposición de holografía tuvo lugar en Michigan en 1968 y la segunda en Nueva York en 1970. En 1971 se fundó una Escuela de Holografía en San Francisco, la primera en la que científicos, ingenieros y artistas podían aprender la nueva técnica. De este modo la holografía se convirtió en un ejemplo inusual de campo científico en el que participaron en su desarrollo grupos de personas de muy distinta procedencia, desde físicos e ingenieros hasta artistas (s.f.).

Tanto tiempo después resulta asombroso que este tipo de imagen, sorprendente y fantasmagórica, no se haya integrado al arte con más frecuencia e intensidad, tal como lo han hecho la fotografía, las técnicas digitales u otros avances tecnológicos.

\section{Referencias}

Abramson, N.H. (2000). Incoherent holography. Recuperado de http:// proceedings.spiedigitallibrary.org/proceeding.aspx?articleid $=921387$

Augier, A. G. (2013) Holograbados, una tecnología creada en Cuba. Revista Anales de la Academia de Ciencias de Cuba. Recuperado de http:// www.revistaccuba.cu/index.php/acc/article/view/146

Beaty, W.J. (1995). Abrasion Holography, hand-draw holograms.

Recuperado de http://amasci.com/amateur/holo1.html_

Benton, S., Greguss, P., Huhtamo, E., Kac, E. \& Koski J. (1999). Kangastus -Mirage, Holografia-taiteen näyttely ..Helsinski: Rauman taidemuseo.

Bohm, D. (2008). La totalidad y el orden implicado (6ta ed.). Barcelona: Kairós

Caufield, H. (Ed.). (2016). The Arte and Science of Holography: A Tribute to Emmett Leith and Yuri Denisyuk. Orlando: SPIE Press.

Chiappiani, R. (2006). Christo and Jeanne-Claude: revealing an object by 
concealing it. Milán: Skira

Cottington. D. (2002). Cubismo: Movimientos en el Arte Moderno (Serie Tate Gallery). Madrid: Ediciones Encuentro.

Dados Negros. Centro de holografía y artes (s.f.). Introducción a la

holografia. Recuperado de http://www.dadosnegros.com/centro-de-

holografia-y-artes/introduccion-holografia/

Dalí, S. (1972) The 3rd Dimension: The 1st World Exposition of Holograms Conceived by Dali. New York: M. Knoedler and Co.

Dueñas, J. (2001). Silencio y vacio. Recuperado de http://www.

realidadesinexistentes.com/silencio-y-vacio

Fer, B., Batchelor, D. \& Wood, P. (1999). Realismo, Racionalismo y

Surrealismo. El arte de las entreguerras (1914-1945) Madrid: Ediciones Akal.

Fernández, J.A. (2004). Tres dimensiones en la historia de la fotografía. La imagen estereoscópica. Málaga: Miramar.

Forbes, F. (2015, 13 de Mayo). ¿Vivimos en un holograma? Es más probable de lo que puedas pensar. Recuperado de https://www.institutodraco. com/es/article/23/-vivimos-en-un-holograma-es-mas-probable-de-loque-puedas-pensar

Gabor, D. (1948, Mayo 15). A new microscopic principle. Nature, 161, 777778

Haupt, G. \& Binder, P. (2001). Shu-Min Lin: entrevista Universes in Universe. Recuperado de http://universes-in-universe.de/car/venezia/ bien49/twn/s-lin-s-int.htm

Huo, N. (2010, 25 de Mayo). Flying colors: holographic art of Dieter Jung. Shenzhen Daily, p. 15

Johnston, S.F. (2006). Holographic visions. A History of New Science .

Oxford : Oxford University Press.

Menna F. (1977). La opción analítica en el arte moderno: figuras e iconos. Barcelona: Gustavo Gili.

Ozaki, M., Kato, J. \& Kawata,S. (2013, 20 de septiembre). Color selectivity of surface-plasmon holograms iluminated with white light Applied Optics, 52 (27), 6788-679

Pérez, J.L. (2015). ¿Qué es un holograma? (el arte holográfico).

Recuperado de http://www.lienzos.net/2011/07/que-es-un-hologramaarte-holografico.html

Sharp,W. (1970, Marzo). Nauman Interview . Arts Magazine , 44, 22-27 
Starick, P. (1995, 13 de septiembre). Holograms reflect our progress. The Advertiser, p. 8

Viera, H. \& Ferreira L. (2006). La Holografía. Recuperado de http://www.revistabiosofia.com/index.php?option=com content\&task=view\&id=115\&Itemid

Angel Alonso: Crítico de arte y artista plástico. Ediciones ARTE CUBANO Consejo Nacional de las Artes Plásticas.

Contact Address: 3ra \#1205 entre 12 y 14. Miramar. Playa. Habana, (Cuba).

E-mail address: angelalonso2010@gmail.com 